\title{
Panorama do percurso acadêmico feminino em um curso de Engenharia de Computação
}

\author{
Derivaldo Machado da Silva ${ }^{1}$, Viviane Almeida dos Santos ${ }^{1}$ \\ ${ }^{1}$ Universidade Federal do Pará (UFPA), Campus Universitário de Tucuruí (CAMTUC) \\ CEP: 68.455-695 - Tucuruí - PA - Brasil \\ Programa de Pós-Graduação em Computação Aplicada (PPCA) \\ derivaldo.silva@ndae.ufpa.br, vsantoseufpa.br
}

\begin{abstract}
Even with the advances of gender issues worldwide, in the computing field, women still suffer with the culture of being unable to handle complex tasks. The present study uses the case study method with a quali-quanti approach to understand the female academic path in a Computer Engineering course. We analized the differences in performance by gender, the permanence and evasion by sex, and the difficulties faced by women in the course. The results highlight the full capacity of women to follow the course, but influencing factors affect their motivation and need to be considered to ensure their permanence until the conclusion of the course.
\end{abstract}

Resumo. Mesmo com os avanços das questões de gênero mundialmente, na computação, as mulheres ainda sofrem com a cultura de que são incapazes para lidar com tarefas complexas. O presente estudo utiliza o método estudo de caso com uma abordagem do tipo quali-quanti para compreender o percurso acadêmico das mulheres em um curso de Engenharia de Computação. Foram analisadas as diferenças de desempenho por gênero, a permanência e evasão entre os sexos, e as dificuldades enfrentadas pelas mulheres no curso. Os resultados destacam a plena capacidade da mulher em acompanhar o curso, porém fatores influenciadores afetam sua motivação e precisam ser considerados para garantir sua permanência até conclusão.

\section{Introdução}

A questão de gênero na computação tem se tornado uma preocupação global, pois, cada vez mais, o número das ingressantes e egressas está em declínio [Lobo 2016; Michell et al. 2018; Silva 2019; Fernández-Cézar et al. 2020]. Este cenário por si só é alarmante e demanda estudos para detectar as dificuldades enfrentadas pelas alunas durante o curso.

Pesquisas anteriores elucidam que o desempenho das mulheres na computação é considerado satisfatório e equilibrado ao dos homens [Pereira et al. 2020; Freitas e Carvalho 2020], no entanto, a cultura patriarcal implicitamente insiste em apontar o contrário [Silva 2019]. Diante disso, mais estudos comparativos sobre desempenho, reprovações em disciplinas por gênero e dificuldades enfrentadas por elas precisam ser conduzidos para esclarecer as reais causas da desigualdade vivenciada por mulheres na graduação desta área.

No curso de Engenharia de Computação (EC) do Campus Universitário de Tucuruí (CAMTUC) da Universidade Federal do Pará (UFPA), 17,01\% são ingressantes mulheres e destas, somente $9,72 \%$ concluem o curso. Para compreender o que ocorre neste cenário, foi conduzido um estudo de caso com abordagem quali-quanti 
para analisar as reprovações, o desempenho, a evasão e as dificuldades das mulheres ingressantes e egressas de sete turmas deste curso. Foram considerados dados coletados no período de 2013 a 2019 sobre as variáveis $n^{\circ}$ de reprovações e evasões por semestre do curso e sexo. Análises estatísticas descritivas e de correlação foram efetuadas. Em seguida, foram realizadas entrevistas com alunas do curso para entender os fatores que mais influenciam nas dificuldades enfrentadas no curso.

Os resultados confirmam que as reprovações independem de gênero e que o desempenho delas nas disciplinas é bem satisfatório no curso, no entanto, há fatores que as afetam desde o início da graduação, que são: a baixa representatividade feminina; o comportamento masculino preconceituoso de professores e alunos; poucas oportunidades de estágio/trabalho; a falta de apoio à gravidez e maternidade; a falta de apoio de familiares, amigos(as), professores e colegas de turma; a falta de conhecimento prévio sobre o curso; e o sentimento de incapacidade de continuar o curso.

O trabalho está organizado da seguinte forma: na Seção 2 são apresentados os trabalhos relacionados; a Seção 3 descreve a metodologia adotada nesta pesquisa; Na Seção 4 são apresentados os resultados e a discussão da pesquisa; e, por fim, na Seção 5 , são descritas as conclusões e trabalhos futuros.

\section{Trabalhos relacionados}

Foram realizadas buscas na BDTD (Base de Teses e Dissertações Nacionais), na revista Estudos Feministas, no Google Acadêmico, e nos eventos WIT, o CBIE e o ANPED, com o objetivo de obter estudos que analisam as dificuldades enfrentadas pelas alunas nos cursos de computação no cenário nacional. Os critérios de qualidade utilizados na seleção das obras foram rigor $^{1}$, credibilidade $^{2}$ e relevância ${ }^{3}$.

Amaral et al. (2017) acompanharam o trajeto acadêmico de alunas no curso de Sistemas de Informação (SI) e concluíram que elas tiveram um desempenho satisfatório, porém sofreram com discriminação de gênero. Outro estudo realizado com alunos de SI e EC aponta que as mulheres são mais sociáveis que os homens e que a participação delas nas equipes de trabalho elevou o desempenho do grupo [Resende et al. 2020].

Pereira et al. (2020) buscaram compreender a relação da média do rendimento por discentes e as disciplinas concluídas e verificaram que os rendimentos das mulheres foram superiores aos dos homens. Por exemplo, em matérias que exigem cálculos matemáticos, as mulheres ultrapassaram em quase $8 \%$ os homens.

Silva (2019) analisou os dados do IBGE sobre os cursos de exatas e descobriu que o desempenho das mulheres tem sido superior nas notas médias dos cursos, porém dificuldades em disciplinas de cursos da computação ainda estão entre os principais problemas enfrentados. Eles alertam que as mulheres na computação desenvolvem comumente a síndrome da impostora, devido às altas demandas de atualização tecnológica associadas à cobrança do estereótipo de perfeição imposto pela sociedade.

Mesmo com as dificuldades enfrentadas pelas mulheres na computação, é possível notar que tais impedimentos não diminuem seus rendimentos, desempenhos e capacidades diante da imensa desigualdade de gênero apresentada na área.

\footnotetext{
${ }^{1}$ Obra possui abordagem completa e apropriada aplicada aos métodos de pesquisa.

${ }^{2}$ Obra possui resultados bem apresentados e significativos.

${ }^{3}$ Obra apresenta utilidade dos resultados para a comunidade de pesquisa.
} 


\section{Metodologia}

Esta pesquisa objetiva analisar o percurso acadêmico das mulheres em um curso de EC por meio de um estudo de caso com uma abordagem quali-quanti. $\mathrm{Na}$ abordagem quantitativa foi realizada uma análise do $\mathrm{n}^{\circ}$ de reprovações por semestre e por sexo das turmas ingressantes no período de 2013 a 2019 para responder: QP1. Há associação entre o número de reprovações por semestre e sexo? As hipóteses nulas $\left(\mathrm{H}_{0}\right)$ e alternativa $\left(\mathrm{H}_{1}\right)$ são descritas como: Ho. $O$ número de reprovações por semestre não depende do sexo; H1. O número de reprovações por semestre depende do sexo.

A compreensão da influência entre a taxa de reprovação por semestre e sexo pode contribuir para elucidar as dificuldades enfrentadas pelas mulheres no curso, pois a reprovação é um fator influenciador conhecido por desestimular a conclusão do curso pelas discentes. A variável dependente deste estudo é o $\mathrm{n}^{\circ}$ de reprovações de estudantes em disciplinas, já as variáveis independentes são semestre e sexo.

Realizou-se a coleta de dados das variáveis no Sistema Integrado de Gestão de Atividades Acadêmicas (SIGAA) no período de Julho a Setembro de 2020 para todas(os) estudantes do curso de 2013 a 2019. Para obter o $\mathrm{n}^{\circ}$ de reprovações por sexo nos semestres das turmas mencionadas, foram utilizados relatórios, listas de alunos ativos e matriculados nos semestres citados, listas com a quantidade de disciplinas reprovadas e históricos acadêmicos dos(as) alunos(as). Levou-se em consideração 3 tipos de situação: reprovações em nenhuma, uma e mais que uma disciplina, pois a contabilização de reprovações acima de duas disciplinas foi bastante reduzida. A técnica de análise de correlação de Pearson [Hair et al. 1998] foi aplicada sobre as variáveis.

$\mathrm{Na}$ segunda etapa foram realizadas entrevistas semiestruturadas através de um questionário com perguntas fechadas e abertas para alunas do curso com o objetivo de compreender os fatores influenciadores na permanência e evasão das alunas. $\mathrm{O}$ questionário baseou-se no roteiro de perguntas de Souza (2017) e estava relacionado ao conhecimento prévio sobre a área para embasar a escolha do curso, apoio de familiares e amigos(as), percepções de diferença devido ao gênero, dificuldades, situações de preconceito e desmotivação no curso. Vinte e cinco alunas de diferentes turmas responderam o questionário. O método de análise de conteúdo foi adotado para alcançar os resultados.

Como ameaças à validade deste estudo, os resultados são específicos de um curso de Engenharia de Computação, o que impossibilita generalizá-los para toda a diversidade de cursos na área. Os dados quantitativos são representativos para o universo em estudo, porém a amostra qualitativa não é representativa para possibilitar a generalização dos resultados, mas é adequada para alcançar o objetivo de pesquisa.

\section{Resultados e discussão}

O curso de Engenharia de Computação em análise possui um total de 335 ingressantes no período de 2013 a 2019. De acordo com CIAC (2020), as mulheres são a minoria, representando apenas $17,01 \%$ de discentes do curso. Na Figura 1 é possível identificar que as mulheres não ultrapassam $25 \%$ em representatividade por ano de ingresso. 


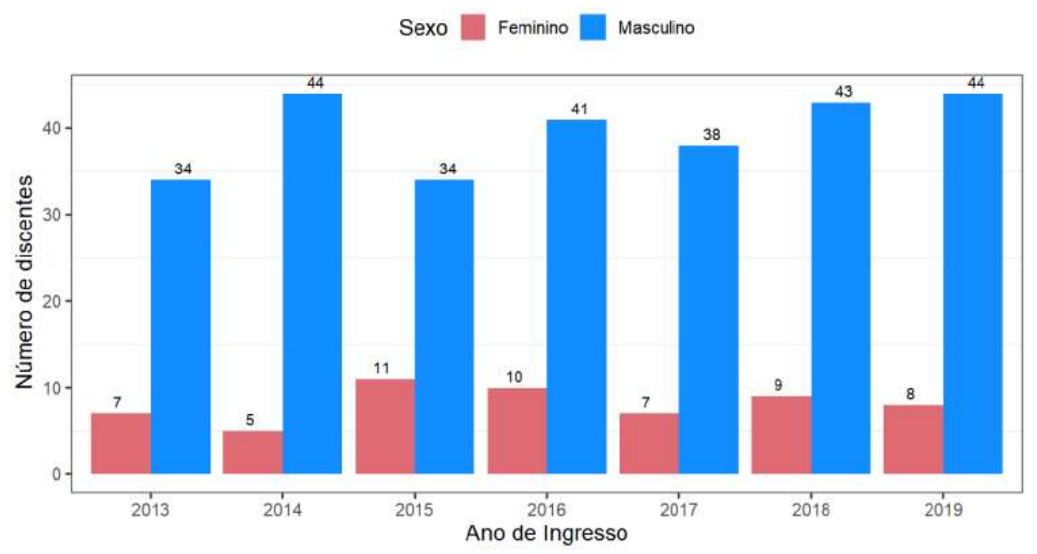

Figura 1. Discentes por sexo e ano de ingresso. Fonte: CIAC (2020).

A taxa de evasão das mulheres do curso é de 35,09\%. Das 57 alunas matriculadas, 20 já desistiram do curso, afetando o número de concluintes mulheres, que tem sido proporcionalmente de $57,14 \%$ de ingressantes do sexo feminino. Na Figura 2 é possível identificar o número de alunas desistentes e concluintes por turma.

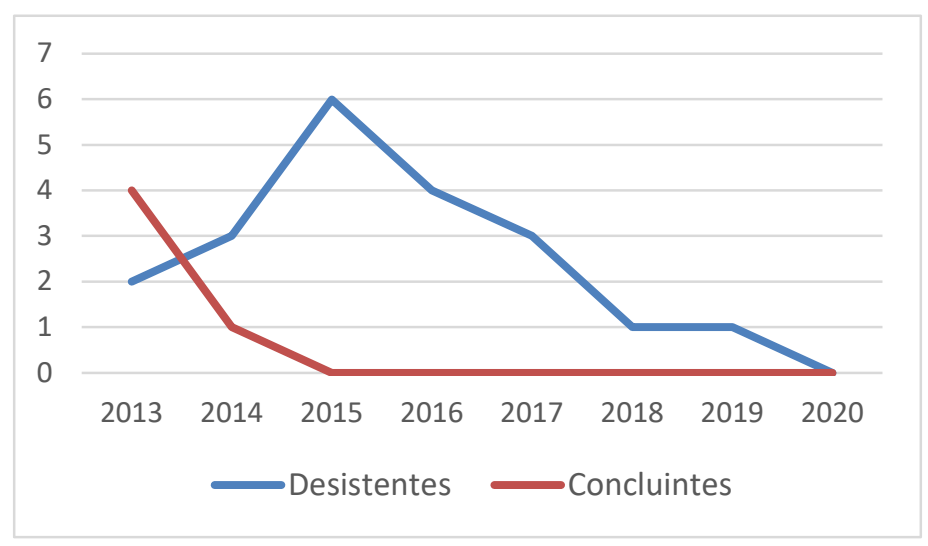

Figura 2. Número de alunas desistentes e concluintes por ano de ingresso.

A seguir são apresentados os resultados deste estudo, os quais foram agrupados em dados quantitativos sobre a reprovação de mulheres e homens por semestre e dados qualitativos sobre as respostas das alunas ao questionário semiestruturado.

\subsection{Análise dos dados quantitativos}

Após a coleta de dados no SIGAA, contamos as reprovações por semestre e sexo. As reprovações ocorrem, na maior parte, até em 2 disciplinas por semestre. Assim, como havia muitos valores zerados para reprovações acima de 2 disciplinas, então agrupamos as reprovações acima de 2 disciplinas. As situações analisadas foram agrupadas da seguinte forma: nenhuma reprovação (Reprovação $=0$ ), uma reprovação $($ Reprovação $=1$ ) e mais de uma reprovação $($ Reprovação $>1$ ) para cada turma (pelo ano de ingresso correspondente). Com este agrupamento, conseguimos minimizar a quantidade de erros do tipo NaN (Not a number - não é um número) no resultado da aplicação da correlação de Pearson que efetuavam divisão por zero.

Foi gerado um relatório detalhado por ano de ingresso (turma) [CAMTUC 2021], para não comprometer o tamanho deste artigo. Após os cálculos detalhados para cada turma, geramos a média, desvio padrão e erro padrão para cada semestre e sexo. 
Nas Figuras 3 e 4 temos as médias de reprovações, considerando todos os anos de ingresso (turmas) por sexo.

É possível perceber que no início do curso as reprovações acima de uma disciplina são maiores, assim como seus respectivos desvios padrão, o que denota que os valores amostrais estão distribuídos em torno da média. Estes diminuem e ficam mais condensados próximos da média a partir do $6^{\circ}$ semestre para ambos os sexos. Da mesma forma, observamos valores mais altos de desvio padrão para as situações de aprovação em todas as disciplinas com o passar dos semestres para as mulheres. Já para os homens os aumentos ocorrem, mas não se elevam da mesma forma. A partir do $7^{\circ}$ semestre as mulheres já não reprovam em mais de uma disciplina e elevam bastante o número de aprovações em todas as disciplinas. Ocorre algo semelhante com os homens, porém ainda aparecem reprovações em todas as situações, apesar de haver uma elevação também no número de aprovação total. Também é possível perceber uma homogeneidade na amostra para a situação de reprovação em uma disciplina. Sendo assim, o curso tem uma medida de dispersão capaz de mostrar que o ${ }^{\circ}$ de reprovações em disciplinas por semestre dos homens varia mais do que das mulheres.

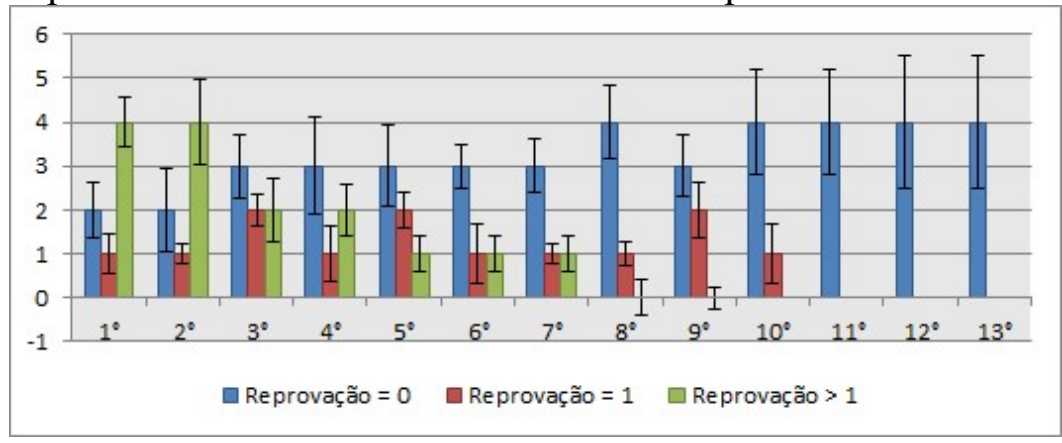

Figura 3. Média de reprovações das mulheres por semestre com desvio padrão.

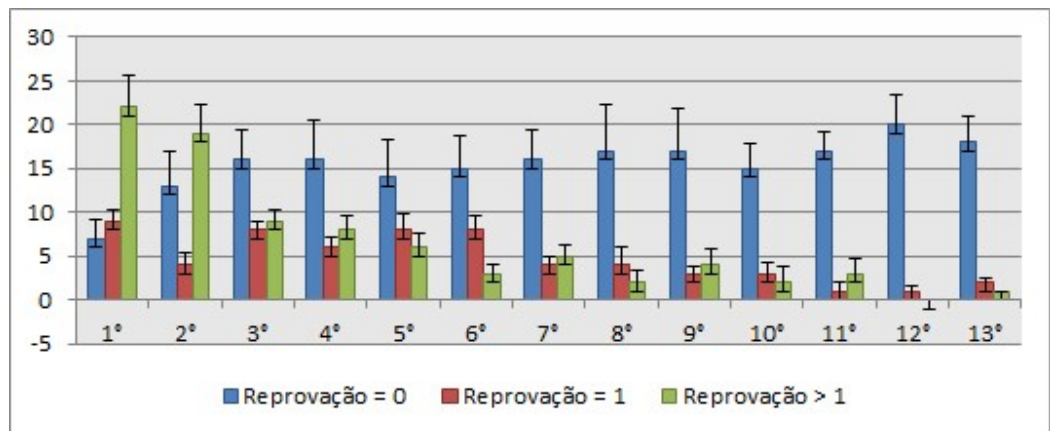

Figura 4. Média de reprovações dos homens por semestre com desvio padrão.

Nas Figuras 5 e 6, proporcionalmente a situação de homens e mulheres se assemelha através das linhas de tendência das reprovações por semestre.

O resultado da correlação de Pearson encontra-se na coluna $\chi 2$ (qui-quadrado), df representa o grau de liberdade e o NS representa o nível de significância da correlação. Nas situações em que o NS apresenta significância, ou seja, menor que 1\%, é possível rejeitar a hipótese nula, caso contrário, pode indicar que não há associação entre as variáveis. Após as colunas relacionadas à correlação, há a coluna sobre o número de evasões daquela turma por semestre e sexo, assim como os totais ao final do semestre. Percentuais da proporção por sexo acima de $30 \%$ estão destacados em negrito e aqueles que tiveram percentuais superiores aos do sexo masculino, estão sublinhados. 


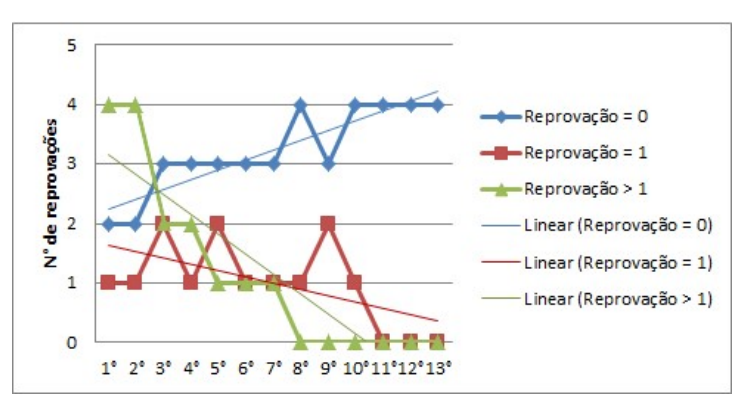

Figura 5. Tendência de reprovações por semestre para mulheres.

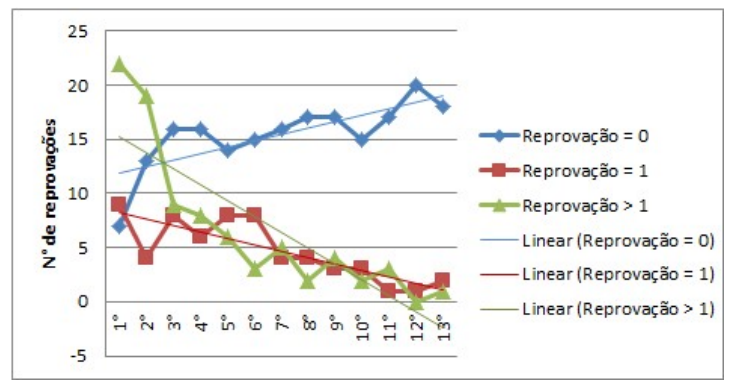

Figura 6. Tendência de reprovações por semestre para homens.

No relatório detalhado é possível analisar a aplicação da correlação para cada turma, porém devido o tamanho do artigo, apresentamos na Tabela 1 os resultados para a turma de 2013 do curso, pois é a mais antiga e representativa em seus valores. É possível observar que, em todas as turmas, o nível de significância (NS) da correlação $(\chi 2)$ é semelhante, portanto a análise feita nesta tabela se repete para as outras turmas. Também é possível observar nesta tabela que o número de aprovações em todas as disciplinas é superior que o de reprovações e, proporcionalmente, as mulheres superam os homens em vários semestres. As ocorrências que as mulheres superam os homens no percentual de reprovações aparecem sublinhadas e comparativamente ocorrem menos. São poucos os casos em que as mulheres superam proporcionalmente os homens em reprovações, quando acima de $30 \%$. Outra informação a ser destacada nesta tabela é a taxa de evasão. Da mesma forma, as evasões ocorrem mais também até o $6^{\circ}$ semestre. Em geral, após este semestre, as mulheres são maioria em aprovação em todas as disciplinas, mesmo tendo algumas exceções. De maneira geral, as mulheres proporcionalmente reprovam menos que os homens. Em mais da metade dos semestres apresentados, 7 exatamente, elas tiveram menos reprovação que os homens.

Tabela 1. Correlação entre reprovações por sexo e semestre da turma de 2013.

\begin{tabular}{|c|c|c|c|c|c|c|c|c|c|c|c|c|c|c|c|c|c|c|c|}
\hline \multirow{2}{*}{$\begin{array}{l}\dot{\bar{\Xi}} \\
\ddot{D}\end{array}$} & \multicolumn{4}{|c|}{ Reprovação = 0} & \multicolumn{4}{|c|}{ Reprovação = 1} & \multicolumn{4}{|c|}{ Reprovação $>1$} & \multirow{2}{*}{$\chi^{2}$} & \multirow{2}{*}{$d f$} & \multirow{2}{*}{ NS } & \multicolumn{2}{|c|}{ Evasão } & \multicolumn{2}{|c|}{ Total } \\
\hline & $\mathbf{F}$ & $\% \mathrm{~F}$ & M & $\% \mathrm{M}$ & $\mathbf{F}$ & $\% \mathrm{~F}$ & M & $\% \mathbf{M}$ & $\mathbf{F}$ & $\% \mathrm{~F}$ & M & $\% M$ & & & & $\mathbf{F}$ & $\mathbf{M}$ & $\mathbf{F}$ & $\mathbf{M}$ \\
\hline $1^{\circ}$ & 5 & $\underline{71,4}$ & 13 & 37,1 & 0 & 0 & 11 & 31,4 & 2 & 28,6 & 11 & 31,4 & 3,82 & 2 & 0,15 & 0 & 0 & 7 & 35 \\
\hline $2^{\circ}$ & 2 & $\underline{33,3}$ & 8 & 23,5 & 1 & 16,7 & 1 & 2,9 & 3 & 50 & 25 & 73,5 & 2,52 & 2 & 0,28 & 1 & 1 & 6 & 34 \\
\hline $3^{\circ}$ & 1 & 20 & 8 & 27,6 & 1 & 20 & 10 & 34,5 & 3 & $\underline{60}$ & 11 & 37,9 & 0,87 & 2 & 0,64 & 1 & 5 & 5 & 29 \\
\hline $4^{\circ}$ & 4 & $\underline{80}$ & 12 & 48 & 0 & 0 & 4 & 16 & 1 & 20 & 9 & 36,0 & 1,92 & 2 & 0,38 & 0 & 4 & 5 & 25 \\
\hline $5^{\circ}$ & 2 & $\underline{40}$ & 5 & 27,8 & 3 & $\underline{60}$ & 9 & 50 & 0 & 0 & 4 & 22,2 & 1,38 & 2 & 0,50 & 0 & 7 & 5 & 18 \\
\hline $6^{\circ}$ & 4 & $\underline{80}$ & 12 & 70,6 & 1 & 20 & 5 & 29,4 & 0 & 0 & 0 & 0,0 & $\mathrm{NaN}$ & 2 & NA & 0 & 1 & 5 & 17 \\
\hline $7^{\circ}$ & 4 & $\underline{80}$ & 11 & 64,7 & 1 & 20 & 3 & 17,6 & 0 & 0 & 3 & 17,6 & 1,03 & 2 & 0,60 & 0 & 0 & 5 & 17 \\
\hline $8^{\circ}$ & 4 & $\underline{80}$ & 13 & 76,5 & 1 & 20 & 2 & 11,8 & 0 & 0 & 2 & 11,8 & 0,79 & 2 & 0,67 & 0 & 0 & 5 & 17 \\
\hline $9^{\circ}$ & 3 & 60 & 12 & 70,6 & 2 & $\underline{40}$ & 2 & 11,8 & 0 & 0 & 3 & 17,6 & 2,64 & 2 & 0,27 & 0 & 0 & 5 & 17 \\
\hline $10^{\circ}$ & 3 & 60 & 12 & 70,6 & 2 & $\underline{40}$ & 4 & 23,5 & 0 & 0 & 1 & 5,9 & $\mathrm{NaN}$ & 2 & NA & 0 & 0 & 5 & 17 \\
\hline $11^{\circ}$ & 5 & $\underline{100}$ & 15 & 88,2 & 0 & 0 & 0 & 0 & 0 & 0 & 2 & 11,8 & $\mathrm{NaN}$ & 2 & NA & 0 & 0 & 5 & 17 \\
\hline $12^{\circ}$ & 5 & $\underline{100}$ & 16 & 94,1 & 0 & 0 & 1 & 5,9 & 0 & 0 & 0 & 0,0 & $\mathrm{NaN}$ & 2 & NA & 0 & 0 & 5 & 17 \\
\hline $13^{\circ}$ & 5 & $\underline{100}$ & 15 & 88,2 & 0 & 0 & 1 & 5,9 & 0 & 0 & 1 & 5,9 & $\mathrm{NaN}$ & 2 & NA & 0 & 0 & 5 & 17 \\
\hline
\end{tabular}

Os resultados das correlações em todas as turmas não apresentam significância inferior a $1 \%$, portanto não possibilitam rejeitar a hipótese $\mathrm{H}_{0}$. Desta forma, a hipótese 
nula é mantida e constatamos que as reprovações não são influenciadas pelo sexo. $\mathrm{O}$ que descarta a suposição de que as mulheres sejam menos capazes que os homens na computação, confirmando o que os estudos relacionados (Seção 2) encontraram. Porém, é necessário analisar em detalhes o que ocorre nas disciplinas dos primeiros semestres, as quais elas proporcionalmente reprovam mais que os homens. Importante notar também que apesar dos valores de correlação identificados, ainda assim não há implicações de causalidade sobre a correlação analisada. Portanto, mais investigações precisam ser feitas para realizar tal afirmação. No caso de resultados da correlação terem dado $\mathrm{NaN}$, outras métricas de correlação também precisam ser consideradas para capturar melhor este cenário sem essa intercorrência, como o modelo linear multinível.

Outro indicador que reforça esta percepção é o valor do CRG (Coeficiente de Rendimento Geral) por sexo [CIAC 2020]. A média deste indicador para as mulheres foi de 4,87, apesar de desempenharem menos que os homens (CRG: 4,91), esta diferença é considerada irrisória $(0,04)$.

\subsection{Análise dos dados qualitativos}

As categorias de análise basearam-se nos fatores levantados por Silva (2019). Estas foram adaptadas com base nas respostas emitidas pelas alunas e estão ilustradas na Figura 7. É possível observar na referida figura as categorias mais relevantes (com maior frequência) que emergiram das respostas através do número de comentários em parênteses por categoria de dificuldades enfrentadas pelas mulheres no curso.

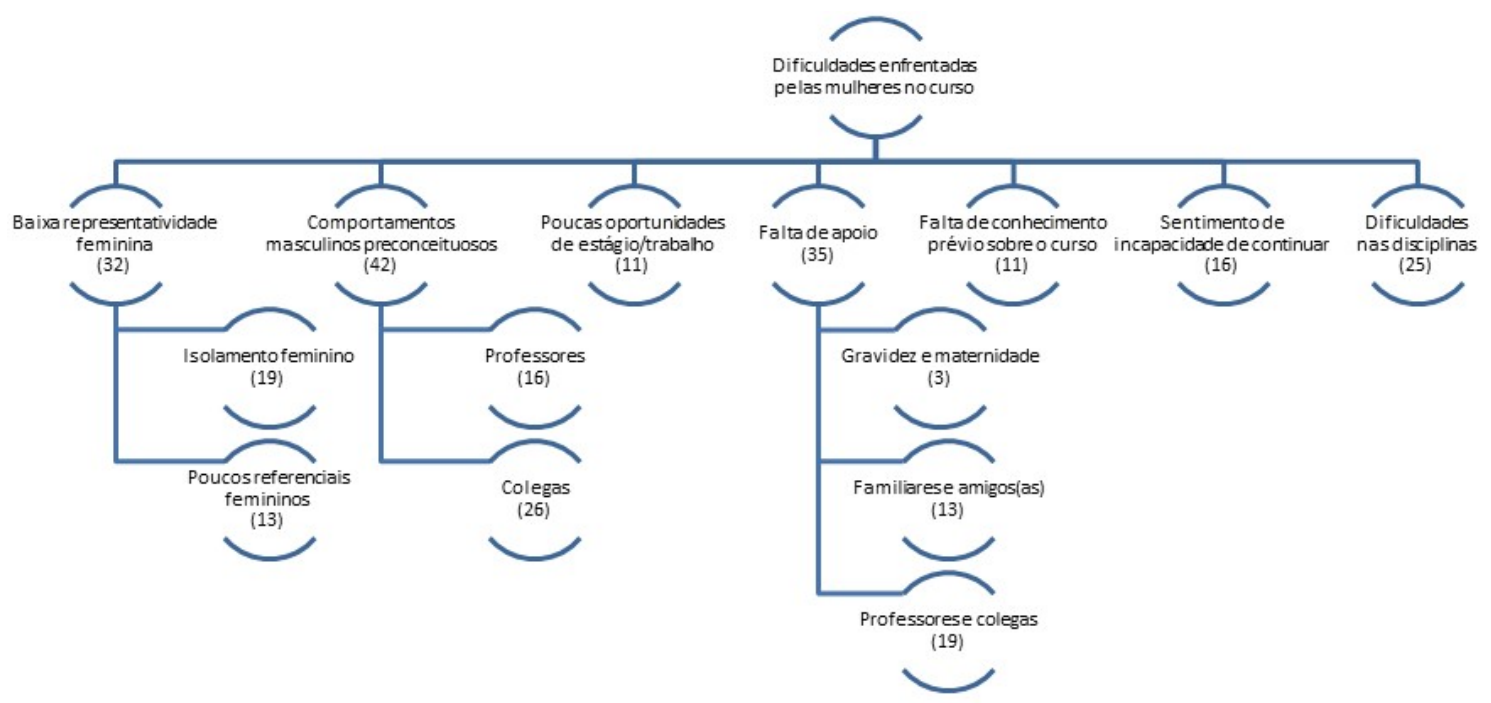

Figura 7. Categorias de dificuldades enfrentadas pelas mulheres.

Apesar da garantia de anonimato das declarações das estudantes, não apresentamos suas declarações, mas descrevemos as nossas conclusões a seguir. A baixa representatividade feminina no curso é um fator que contribui para a existência de isolamento feminino e poucos referenciais femininos para se espelhar, que poderiam ser mais atenuadas com mais professoras e mais alunas ingressando no curso.

Outro grande fator influenciador no desempenho delas é o comportamento masculino preconceituoso de professores e colegas em relação a elas, pois foram relatadas muitas situações de preconceito de gênero provocadas por eles. 
Muitas reclamam das poucas oportunidades de estágio/trabalho na área e consideram um forte fator de desistência do curso, pois remete a sensação de que também não terão oportunidade no mercado de trabalho.

Outra questão latente no curso é a falta de apoio à gravidez e maternidade, visto que os professores, em geral, não consideram de maneira justa as dificuldades enfrentadas ainda mais pelas mulheres que são mães e cursam a faculdade.

A falta de apoio tanto da família/amigos(as), quanto de professores e colegas de turma também são considerados fatores influenciadores importantes. Na percepção delas, a falta de conhecimento prévio sobre o curso também as deixam em posição de desvantagem em relação aos alunos.

Quando questionadas sobre as dificuldades no curso, muitas comentam que o início do curso é mais difícil, porém, as dificuldades nas disciplinas afetam ambos os sexos, o que corrobora o observado nas tendências de reprovações das Figuras 5 e 6 . Por fim, como consequência dos outros fatores, elas apontam o sentimento de incapacidade de continuar como um fator influenciador catalisador da vontade de desistir do curso.

As situações relatadas nas categorias ilustram as principais dificuldades enfrentadas pelas mulheres no curso, que destacam a existência de um ambiente desconfortável e, de certa forma, opressor para as mulheres do curso, como também é relatado por Amaral et al. (2017), Silva (2019) e Martins et al. (2019).

É possível concluir que, no curso analisado, as mulheres não possuem desempenho pior nas disciplinas que os homens. Isto é verificado tanto pela falta de correlação entre reprovações por sexo nos semestres do curso, quanto pelos relatos das alunas. Porém, há outros fatores a serem considerados em melhorias nos cursos para minimizar o contexto desigual e abusivo vivido por elas durante a graduação.

Mello et al. (2019) relatam que mais de $86 \%$ dos professores dos cursos de computação não percebem as desigualdades entre mulheres e homens. Os autores dizem que a falta de percepção, levam as pessoas a cometerem atitudes machistas e desferirem piadas sexistas, o que pode impactar decisivamente na vida acadêmica e profissional das mulheres. Nesse contexto, as mudanças necessárias perpassam, em maior grau, o combate ao machismo estrutural que as alunas enfrentam com familiares, amigos, professores e alunos, através de discursos que reforçam uma falsa inaptidão ou incapacidade de cursar EC até sua conclusão [Oliveira et al. 2019]. Para amenizar este problema, é necessário o desenvolvimento de ações e projetos contínuos para conscientizar e empoderar as alunas [Bordin et al. 2020], assim como políticas de conscientização e capacitação de professores e alunos, seguidas de avaliações periódicas para contemplar melhorias comportamentais, metodológicas e ambientais no curso.

Também anteriormente à graduação, é absolutamente necessário incluir a computação nos currículos escolares, com uma infraestrutura mínima associada a níveis de maturidade (básico, intermediário e avançado) da escola na adoção de tecnologias educacionais [CIEB 2018]. Ribeiro (2019) ressalta que é necessário definir diretrizes, habilidades e conceitos a serem desenvolvidos em cada etapa escolar. 


\section{Conclusões e trabalhos futuros}

Este estudo de caso com abordagem quali-quanti investigou o desempenho e as principais dificuldades enfrentadas pelas mulheres em um curso de EC através da coleta de dados quantitativos sobre reprovação e evasão por sexo, e testemunhos das alunas sobre as dificuldades que enfrentam.

Constatou-se que reprovação não depende de gênero, no entanto, a baixa representatividade feminina; o comportamento masculino preconceituoso de professores e alunos; poucas oportunidades de estágio/trabalho; a falta de apoio à gravidez e maternidade; a falta de apoio de familiares, amigos(as), professores e colegas; a ausência de conhecimento prévio sobre o curso; e o sentimento de incapacidade de continuar o curso destacaram-se como principais dificuldades enfrentadas por elas.

Ações sugeridas na literatura, como políticas de conscientização, capacitação e maior uso das tecnologias no ensino básico podem impactar positivamente neste cenário de desigualdade de gênero, bem como a importância de dar continuidade a este estudo ampliando de maneira crítica as questões culturais e sociais do contexto educacional, as correlações entre matriz curricular, períodos acadêmicos, corpo docente e discente, projetos de extensão, pesquisa e ensino, como elementos educacionais influenciadores na permanência das estudantes e de suas percepções de representação e acolhimento. Iniciativas deste tipo precisam ser aprimoradas em trabalhos futuros, seguidas de avaliações periódicas para contemplar melhorias no curso.

\section{Referências}

Amaral, M. A., Emer, M. C. F. P., Bim, S. A., Setti, M. G. (2017) "Investigando questões de gênero em um curso da área de Computação", Estudos Feministas, Florianópolis, 25(2): 562, maio-agosto.

Bordin, A. Finger, A. Gindri, L. Mello, A. (2020) "Tutoria das Gurias: Uma ação de acompanhamento de alunas ingressantes em cursos de Computação", https://sol.sbc.org.br/index.php/wit/article/view/11283.

CAMTUC - Campus Universitário de Tucuruí da UFPA (2021) "Dados e correlações estatísticas sobre o desempenho de discentes ingressantes no período de 2013-2020 do curso de engenharia de computação - Tucuruí", https://drive.google.com/file/d/1EhZKNYcWxixw0ObdL1_ONK3B9YYfy0j4/view? usp=sharing

CIAC - Centro de Registro e Indicadores Acadêmicos da UFPA (2020) "Dados sobre a evasão dos discentes ingressantes no período de 2013-2019 do curso de engenharia de computação - Tucuruí", https://bityli.com/W36Lt.

CIEB. Centro de Inovação para a Educação Brasileira. (2018) "Níveis de maturidade da escola na adoção de tecnologia", http://www.cieb.net.br/cieb-notas-tecnicas-niveisde-maturidade-na-adocao-de-tecnologia-pela-escola.

Fernández-Cézar, R.; Garrido, D.; García-Moya, M.; Gómezescobar, A.; Solano-Pinto, N. (2020) "Equity or Stereotypes in Science Education? Perspectives from PreUniversity Students", Sustainability, 12, 9354, doi:10.3390/su12229354. 
Freitas, M. J. T., Carvalho, M. E. P. (2020) Mulheres no alunado da computação: o que dizem os números? In Anais do XXV ANPED - Associação Nacional de Pesquisa e Pós-Graduação em Educação, ISSN: 2595-7945.

Hair, J. F., Black, W. C., Babin, B. J., Anderson, R. E. (1998), Multivariate Data Analysis. Prentice Hall.

Lobo, A. (2016) "Mulheres precisam entrar na TI e ir além da programação", http://www.sbc.org.br/2-uncategorised/1903-mulheres-precisam-entrar-na-ti-e-iralem-da-programacao, acessado em 02/09/2020.

Martins, A., Santos, J. e Dantas, A. (2019) "Fatores que Atraem e Afastam as Meninas de cursos da Área de TI". In Anais do XIII Women In Information Technology (WIT), Sociedade Brasileira de Computação, p. 114-118, Belém/PA.

Mello, A., Melo, A. e Ferrão, I. (2019) "Uma análise sobre questões de gênero nos cursos de Computação do município de Alegrete/RS”. In Anais do XIII Women In Information Technology (WIT), Sociedade Brasileira de Computação, p. 61-68.

Michell, D., Szabo, C., Falkner, K., Szorenyi, A. (2018) "Towards a socio-ecological framework to address gender inequity in computer Science", Computers \& Education, 126, pp. 324-333, ISSN 0360-1315.

Oliveira, C. Oliveira, K. Barbosa, A. Ferreira, H. Neta, M. (2019) "Projeto divas: desenvolvimento de ações socioeducativas para inclusão, desmistificação e empoderamento da mulher em tecnologias da informação e comunicação", Conexões - Ciência e Tecnologia, v. 13, n. 5, p. 44-54.

Pereira, J. Moura, L. Coelho, N. Montes, G. Magesti, I. Coelho, A. (2020) "Uma Análise da Participação das Mulheres nos Cursos Técnico em Informática e Ciência da Computação do Instituto Federal do Sudeste de Minas Gerais”. In Anais do XIV Women In Information Technology (WIT), Sociedade Brasileira de Computação, p. 139-148.

Resende, D. Jr, L. Berardi, R. (2020) "Influência da diversidade de gênero e da sociabilidade no desempenho acadêmico de equipes de estudantes de graduação em Computação - uma análise preliminar". In Anais do $31^{\circ}$ Simpósio Brasileiro de Informática na Educação, Sociedade Brasileira de Computação, p. 1363-1372.

Ribeiro, L. (2019) "Ensino de computação na educação básica: as diretrizes da SBC", Revista da Sociedade Brasileira de Computação, http://www.sbc.org.br/images/flippingbook/computacaobrasil/computa_41/pdf/Comp Brasil_41.pdf.

Silva, A. K. R. (2019) "Motivações e desafios para entrada e permanência de mulheres na área de Tecnologia: Estudo de Caso no Centro de Informática da UFPE”. Trabalho de Conclusão de Curso. Engenharia da Computação do Centro de Informática da Universidade Federal de Pernambuco, Recife, PE.

Souza, J. J. (2017) "Mulheres na TI: Análise da Inserção e Situação das Mulheres na Área de Tecnologia da Informação na Grande Florianópolis". Trabalho de Conclusão de Curso. Sistemas de Informação da Universidade do Sul de Santa Catarina. Palhoça, SC. 